\title{
VERDADE E FLECHAS NA RETÓRICA E NA ESTÉTICA DOS ANTIGOS PERSAS
}

\author{
Edrisi Fernandes ${ }^{1}$
}

\begin{abstract}
Resumo
Friedrich Nietzsche foi um filólogo e filósofo saxão que estudou muito a retórica dos antigos, e algumas de suas anotações (de 1872?) são conhecidas como Curso de Retórica. Em sua obra mais importante, Assim Falava Zaratustra (1885), por meio de seu personagem-título, Nietzsche dá voz a um profeta persa redivivo, que em certa passagem afirma: "'Dizer a verdade e saber manejar bem o arco e as flechas' - Isso parecia caro, ao mesmo tempo que difícil, para o povo donde vem o meu nome". A afirmação de Zaratustra, ecoada por Nietzsche, fundamenta-se em Heródoto (Histórias, I.136), que disse que os persas ensinavam aos seus filhos apenas três preceitos: cavalgar, manejar o arco e flecha e dizer a verdade. Estudamos o Avesta (o livro mais sagrado do zoroastrismo), alguns textos da época Aquemênida, escritos em persa antigo (veteropersa), bem como algumas representações icônicas Aquemênidas, com a intenção de mostrar aquilo que os mesmos podem nos ensinar sobre a associação entre a verdade e as flechas na retórica e na estética dos antigos persas, devotos do deus Ahura-Mazdâ. Uma passagem do Avesta (com seu estrato mais antigo escrito numa língua iraniana oriental, o "avéstico") vincula diretamente a verdade e as flechas quando elogia o (mítico) rei Vishtâspa, patrono de Zaratustra, como sendo "aquele que com arco e flecha procurou espaço para a Verdade, que com arco e flecha encontrou espaço para a Verdade, que concordou em ser o braço e o suporte da religião de Ahura [-Mazdâ], de Zaratustra" [Zam (Zamyâd) Yasht do Khorda (Pequeno) Avesta, 85 (Yasht, 19.85)]. Nesta investigação, analisamos o lugar privilegiado do conceito de Asha ("Verdade/Retidão/Ordem") na religião zoroastriana e o emprego ideológico, retórico e estético de associações com esse conceito promovidas pelos soberanos Aquemênidas, e revisamos algumas passagens veteropersas e de Heródoto onde o antigo ato persa de disparar flechas tem vinculação com sua retórica.
\end{abstract}

Palavras-chave: Aquemênidas; Estética; Ética Zoroastriana; Retórica; Zoroastrismo.

\begin{abstract}
Friedrich Nietzsche was a Saxon philologist and philosopher who studied enthusiasticaly the rhetoric of the ancients, and some of his notes (from 1872?) are known as his Course "on Rhetoric". In his most important work, Thus Spake Zarathustra (1885), through his titlecharacter Nietzsche gives voice to a revived Persian prophet who, in a certan passage, affirms: "To tell the truth and to handle the bow and arrow well' - that seemed both dear and difficult to the people who gave me my name". Zarathushtra's affirmation, echoed by

\footnotetext{
${ }^{1}$ Edrisi Fernandes é Médico praticante, bem como Especialista, Mestre e Doutor em Filosofia. Estudioso das trocas culturais na antiguidade e da transmissão da herança dos antigos, fez estudos pós-doutorais em Estudos Clássicos na UnB. Atualmente é Pesquisador e Professor Colaborador da Cátedra Archai (Unesco/UnB) e do Programa de Pós-Graduação em Filosofia (UFRN)
} 
Nietzsche, is grounded in Herodotus (Histories, I.136), who said that the Persians taught their children only three precepts: to ride a horse, to shoot an arrow, and to tell the truth. We have studied the Avesta (Zoroastrian most holy book), some texts from the Achaemenid era, written in Old Persian, as well as some Achaemenid iconic representations, with the intention of showing what they can teach us about the association between truth and arrows in the rhetoric and aesthetic practices of the ancient Persians, devouts of the god Ahura-Mazdâ. A passage from the Avesta (with its oldest stratum written in an oriental Iranian language, "Avestan"), directly associates truth with arrows when it praises the (mythical?) king Vishtâspa, patron of Zarathushtra, as he "who with bow and arrows has sought space for truth, who with bow and arrows has found space for truth, he who agreed to be the arm and support of the religion of Ahura[-Mazdâ], of Zarathushtra" [Zam (Zamyâd) Yasht of the Khorda (Small) Avesta, 85 (Yasht, 19.85)]. In this investigation we analyse the privileged place of the concept of Asha ("Truth/Righteousness/Order") in the Zoroastrian religion and the ideologic, rhetoric and aesthetic use of associations with that concept promoted by the Achaemenid sovereigns, and we review some passages in Old Persian and from Herodotus where the ancient Persian act of shooting arrows has a link with Persian rhetoric.

Keywords: Achaemenid aesthetics; Achaemenid rhetoric; Zaratushtra (Zarathushtra); Zoroastrian ethics; Zoroastrian religion.

\section{INTRODUÇÃO}

Em sinal da submissão dos demais povos, os persas apreciavam receber como presente terra e água (cf. p. ex. Heródoto, Hist. IV.126). Tendo recebido do rei Dario uma mensagem conclamando-o a oferecer um presente de terra e água e vir conferenciar, Idanthyrsus, rei dos citas, respondeu: "Em vez de dar-te terra e água, os presentes que pedes, mandar-te-ei aqueles que mereces receber [ou: os mais apropriados]" (Hist. IV.127), e enviou (de parte com os outros reis citas) como presente um pássaro, um rato, uma rã e cinco flechas (Hist. IV.131). Segundo Heródoto, os persas indagaram do portador o significado desses presentes, mas ele disse que aqueles, se fossem bastante inteligentes, entenderiam por si mesmos o significado da oferenda.

Deliberando sobre esse assunto após reunir suas tropas (Hist. IV.132), Dario chegou à conclusão que, com aqueles estranhos presentes, os citas lhe haviam oferecido terra e água como sinal de submissão. Imaginara isso porque o rato, assim como o homem, nasce na terra e se alimenta de trigo; a rã nasce na água; o pássaro é ágil e veloz como o cavalo, animal muito estimado pelos persas, e as flechas, enfim, seriam um símbolo da rendição. Assim 
supôs o soberano persa, mas o conselheiro real Góbrias ${ }^{2}$ (conquistador da Babilônia para a Pérsia; sogro de Dario e depois marido de sua irmã) chegou a uma conclusão diferente que se apressou em transmitir às tropas falando assim: "Persas, estes presentes significam que, [no entendimento dos citas,] se não voares pelos ares como os pássaros, se não vos esconderes debaixo da terra como os ratos, se não saltares nos pântanos como as rãs, não tomareis a ver vossa pátria, pois morrereis trespassados por flechas" (Hist. IV.132). Por esse relato percebese que o significado dos símbolos não é necessariamente transcultural, e que a interpretação apropriada de uma mensagem não é empreitada fácil para quem não está familiarizado com valores culturais alheios.

É clássica a associação das flechas com a linguagem entre os antigos persas, que empregaram originariamente escritas que chamamos de cuneiformes, mas que os anglófonos por vezes chamam de "arrow-headed inscriptions", inscrições com pontas de flechas. Não é impossível que essa analogia visual tenha sido antes, em algumas ocasiões, apropriada pela retórica e estética dos persas, que tiveram reis que se apresentaram, em grandes inscrições murais em cuneiforme e nos relevos a elas associados, como mestres da verdade e grandes flecheiros (em português atualmente se usa mais a palavra "arqueiro" que "flecheiro"; em veteropersa, essas palavras se traduziam literalmente por thanuvaniya e tirandaz).

Estudamos alguns textos da época Aquemênida, originalmente escritos em veteropersa, e analisamos também algumas passagens das escrituras sagradas do zoroastrismo, no idioma avéstico, com a intenção de mostrar o que essas locuções podem nos ensinar sobre a associação entre a verdade e as flechas na retórica dos antigos persas.

\section{A CONTRIBUIÇÃO DE NIETZSCHE E DE HERÓDOTO}

Friedrich Nietzsche foi um filólogo e filósofo que estudou muito a retórica dos antigos, e algumas de suas anotações (de 1872?) são conhecidas como Curso de Retórica. Ali, Nietzsche nos recorda que "a retórica emerge de um povo que vive ainda em meio a imagens míticas e que ainda não conhece a absoluta necessidade da fidelidade histórica: ele prefere ser persuadido a ser instruído" (NIETZSCHE 1999, 29). Lembra-nos ainda que "a Retórica é o aperfeiçoamento de artifícios que repousam na linguagem" [grifo original]; não existe

${ }^{2}$ Gôbrýas em grego; Gaubaruva em veteropersa. 
nenhuma "naturalidade" não-retórica da linguagem à qual se possa apelar, e a própria linguagem é o resultado da retórica. "A força de descobrir e fazer valer o que em cada coisa é eficiente e impressiona, que Aristóteles chama Retórica, é também a essência da linguagem”. Como a retórica, a linguagem não repousa na essência das coisas, no verdadeiro, "ela não quer instruir [sobre o real], mas sim transmitir ao outro uma excitação e uma impressão subjetivas" (NIETZSCHE 1999: 37).

Infelizmente Nietzsche não tratou dos antigos persas em seu Curso de Retórica na Universidade de Basileia. Mas aquilo que Nietzsche nos diz acerca da retórica dos gregos e romanos não se afasta muito daquilo que sabemos sobre a retórica e a estética dos antigos persas, e sobre estas Pierre Briant nos recorda que as inscrições e os relevos dos Aquemênidas "são destinados prima facie a impor e transmitir a imagem de um poder universal intangível"; a retórica aquemênida é nutrida mais por assunções ideológicas do que pela realidade, a qual é por ela capturada, mas sobretudo transformada e esteticamente sublimada (BRIANT $2002^{3}$ : $185)$.

Em sua obra mais importante, Assim Falava Zaratustra (1885), por meio de seu personagem central, Nietzsche dá voz a um profeta persa redivivo e, apesar da distorção provocada por essa "ressurreição" numa outra língua e num outro tempo, é impressionante que uma das passagens mais poéticas e angulares da obra evoque a técnica favorita da poesia gática ${ }^{4}$ (do Zaratustra iraniano), a composição dita "anelar" ("ring composition") 5 para falar precisamente do círculo (ring) do eterno retorno, ideia vinculada por Nietzsche ao retorno de Zaratustra:

${ }^{3}$ Para algumas críticas a essa tradução cf. James Davidson (2003), "Versailles with Panthers". London Review of Books, 25 (13): 7-10.

${ }^{4}$ Dos Gathas, 17 hinos em "veteroavéstico" que se acredita terem sido compostos pelo Zaratustra iraniano, e que fazem parte da Yasna, a coleção fundamental de passagens litúrgicas do Avesta (o livro mais sagrado do zoroastrismo).

${ }^{5}$ Cf. Helmut Humbach (1957 [ed. revista]), "Gast und Gabe bei Zarathushtra" [1952]. Münchener Studien zur Sprachwissenschaft, pp. 5-34, especialmente pp. 8 e 15) Wolfgang Lentz (1953), "Yasna 47”. Zeitschrift der Deutschen Morgenländischen Gesellschaft, 103: 318-343 (especialmente a p. 340); Hanns-Peter Schmidt (1968), “Die Komposition von Yasna 49”, em: J. C. Heesterman, G. H. Schokker, V. I. Subramoniam (eds.), Pratidānam: Indian, Iranian and Indo-European studies presented to Franciscus Bernardus Jacobus Kuiper on his 60th birthday. Mouton, Haia, pp. 170-192 (especialmente as pp. 187, 192); H.-P. Schmidt (1974), "Associative technique and symmetrical structure in the composition of Yasna 47”. Em: R. N. Frye (ed.), Neue Methodologie in der Iranistik. Otto Harrassowitz, Wiesbaden, pp. 306-330; H.-P. Schmidt [com contribuições de W. Lentz e S. Insler] (1985), Form and Meaning of Yasna 33. New Haven (Connecticut): American Oriental Society, p. 47; Mary Douglas (2007), Thinking in Circles: An essay on ring composition. Yale University Press, N. Haven/Londres, pp. 64-66, 144. 


\begin{abstract}
Alles geht, Alles kommt zurück;/ ewig rollt das Rad des Seins.//
Alles stirbt, Alles bluht wieder auf,/ ewig läuft das Jahr des Seins.//

Alles bricht, Alles wird neu gefügt;/ ewig baut sich das gleiche Haus des Seins.//

Alles scheidet, Alles grüßt sich wieder;/ ewig bleibt sich treu der Ring des Seins.
\end{abstract}

(Assim Falava Zaratustra, III, “O convalescente”, 2; cesuras nossas) ${ }^{6}$.

Em certa passagem, o Zaratustra nietzscheano afirma: “'Dizer a verdade e saber manejar bem o arco e as flechas' - isso parecia caro, ao mesmo tempo que difícil, para o povo donde vem o meu nome" (Assim Falava Zaratustra, I, "Dos mil alvos e do único alvo"). A ética zoroastriana (a "virtude persa") recomenda pensar, falar e agir conforme Asha (conforme a Ordem/Verdade/Retidão, i. e, "virtuosamente") ${ }^{7}$. Em sua autobiografia, Nietzsche reafirma: "Falar a verdade e atirar bem com flechas, eis a virtude persa" (Ecce Homo, "Por que sou um destino", 3 [itálico original]). A afirmação de Zaratustra, ecoada por Nietzsche, fundamentase em Heródoto (Hist. I.136), que afirmou que os persas educavam seus filhos, dos 5 aos 20 anos, segundo apenas três preceitos: cavalgar, manejar o arco e flecha e dizer a verdade ${ }^{8}$. Robert Drews (2004: 166 n. 38) acredita que Heródoto assimilou esse aforismo a partir da Periegesis de Hecateu de Mileto (fl. sécs. VI-V a.C.).

Os autores clássicos conheceram alguns dos motivos da ideologia monárquica Aquemênida, como por exemplo, que o Rei dos Reis (DB §8; DNa §3; DSe §3-4; XPh §3) ${ }^{9}$ era um experimentado caçador, a personificação da Verdade e da Lei, bem como o mais firme inimigo da mentira (AHN 1992: 229-245). Apresentarei a seguir alguns entendimentos da percepção ideológica, retórica e estética persa quanto à verdade e às flechas, a partir de textos aquemênidas e de escrituras sagradas muito antigas do zoroastrismo, bem como de algumas representações icônicas oriundas dos persas e das culturas persianizadas.

\footnotetext{
6 "Tudo vai, tudo retorna;/ eternamente gira a roda do ser.// Tudo perece, tudo refloresce,/ eternamente transcorre o ano do ser.// Tudo se esfacela, tudo se rejunta;/ eternamente constrói-se a mesma casa do ser.// Tudo se separa, tudo se reencontra;/ eternamente segue leal a si mesmo o anel do ser" (trad. nossa).

${ }^{7}$ Cf., p. ex., a Yasna, 8.7; 10.16; 11.17; 30.3; 35.2-3 e 36.5; 51.1; Yasna Haptanghâiti, 1.2; 2.5 ; 4.1 etc.

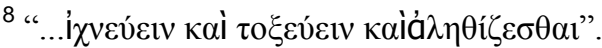

${ }^{9}$ DB = inscrição de Dario o Grande em Behistun (Behishtan, Bagastana, Bîsotûn); DNa = inscrição "A" de Dario em Naqsh-i Rustam; DSe = inscrição "E" de Dario em Susa; XPh = inscrição "H" de Xerxes em Persépolis (as abreviações referem-se apenas aos textos em veteropersa). Cf. ANÔN. Old Persian Texts (s/d), e ANÔN. The inscriptions of Old Persian cuneiform of the Achaemenian emperors (1964).
} 


\title{
A "VERDADE" (VETEROPERSA ARTA [SÂNSCRITO ritÁ], AVÉSTICO ASHA, PÁLAVI ARD)
}

O livro mais sagrado dos zoroastrianos traz duas passagens que elogiam o [mítico?] rei Vishtâspa, patrono de Zaratustra, como sendo "aquele que com arco e flecha (druca paurvãnca) ${ }^{10}$ procurou espaço (ravô) para a Verdade (Asha), que com arco e flecha encontrou espaço para a Verdade, que concordou em ser a arma e o suporte da religião de Ahura [-Mazdâ] ${ }^{11}$, de Zaratustra"12 [Frawardin (Farvardin) Yasht do Khorda (Pequeno) Avesta, 99 (Yasht, 13.99) ${ }^{13}$; Zam (Zamyâd) ${ }^{14}$ Yasht do Khorda Avesta, 85 (Yasht, 19.85)].

Traduzir o vocábulo avéstico Asha e o veteropersa Arta como "Verdade" é reduzir enormemente seu significado, que compreende as noções de "Verdade", "Retidão" e "Ordem", mas também a ideia de "Existência" $" 15$ ou de "Aquilo que está estabelecido"16. Uma

\begin{abstract}
${ }^{10}$ Em relação a essa expressão seguimos Harold Walter Bailey [(1961) “Arya III". Bulletin of the School of Oriental and African Studies (Londres), 24, parte III: 470-483, p. 470-73], que se apóia numa relação entre o avéstico druca (onde o -ca é secundário) e o veterokhotanês durna- (onde o -rn é secundário), sogdiano $d h r$ 'wn, pálavi drwn/drôn, vasi-vari (prasun[i]) duru-, farsi durônah, "arco" e entre uma suposta forma avéstica *parvan e o veterokhotanês pûrna- (onde o -rn é secundário), "flecha" (relacionado a um antigo radical indoiraniano, par-, significando "flutuar no ar; voar"). Bailey (p. 473) decompõe parvãnca em parvan- + -ca, e logo em par- + -van- + -ca. A tradução de druca paurvãnca por "with bow and arrow" aparece em William W. Malandra (1983), An Introduction to Ancient Iranian Religion: readings form the Avesta and the Achaemenid inscriptions. University of Minnesota Press, Minneapolis, pp. 96 (Yasht, 19.85) e 115 (Yasht, 13.99).
\end{abstract}

11 Ahura ou ahurô vem de ahû, "existência". Ahû relaciona-se ao sânscrito asu, "vida; força vital" e ao antigonorueguês āss, "deus" (plural aesir). Na Yasna, 71, aprendemos que a "forma"/a "carne"/o "corpo" (avéstico kehrp) de Ahura-Mazdâ é a ordem da criação. Mazdâ é um vocábulo cognato com o substantivo védico medhá [medhás em su-medhás ("que tem boa percepção mental ou sabedoria; sábio")], "percepção mental; sabedoria" [cf. Mary Boyce(1975), A History of Zoroastrianism, vol. I. The early period. E. J. Brill, Leiden, p. 37 e ss.].

12 “... yô druca paurvãnca ashâi ravô yaêsha, yô druca paurvãnca ashâi ravô vîvaêdha, yô bâzushca upastaca vîsata ainghao daênayao, yat ahurôish zarathushtrôish". Tradução baseada em Helmut Humbach \& Pallan R. Ichaporia [em: ANÔN. Zamyâd Yast: Yasht 19 of the Younger Avesta (1998), p. 56; cf. pp. 160-161], substituindo "with stock and knots" por "with bow and arrow" e traduzindo "Ahurian Zarathushtrian Religion" por "religion of Ahura[-Mazdâ], of Zarathushtra" (tradução alternativa: "existential religion of Zarathushtra").

13 Eis a tradução que Bailey (op. cit., pp. 470-71) propõe para a Yasht, 13.99 (... kavôish vîshtâspahe ashaonô fravashîm yazamaide, takhmahe tanumãthrahe, darshi-draosh âhûiryehe, yô druca paurvãnca ashâi ravô yaêsha, yô druca paurvãnca ashâi ravô vîvaêdha, yô bâzushca upastaca vîsata ainghao daênayao, yat ahurôish zarathushtrôish): "We honour with yasna-rite the fravashi-warden of the kavi-ruler Vishtaspa who maintains the (Zoroastrian) truth, of the bold one, the incarnate gospel, possessor of the fierce wood (spear), devoted to the Ahura-lord, who from bow and arrow got open space for truth, who found out open space for truth, who with arms and with aid was trusty knight for this faith, which is the Ahura-lord's and Zoroaster's".

14 Também conhecido como Khwarenah Yasht.

15 Bernfried Schlerath (1987), “Aša: Avestan Aša”. Encyclopaedia Iranica, 2. Routledge \& Kegan Paul, Nova Iorque, pp. 694-696; p. 695.

16 Gary D. Miller (1968), “rt-Clusters in Avestan”. Language, 44 (2.1): 274-283, p. 274. 
passagem de Heródoto (Histórias, I.96.3 e ss.) mostra o rei medo Deioces17, um administrador justo (I.100.1), a julgar "de acordo com a retidão" (katà tò orthón) e depois fazer seus concidadãos saberem que sua decisão foi tomada "de acordo com aquilo que é" (katà tò eón). Fica muito claro, para qualquer conhecedor da antiga cultura iraniana, que, por trás do juízo de Deioces, encontra-se a ideia essencial de Asha/Arta. Conforme Tom Holland, no entendimento dos persas:

Somente um persa poderia entender o que a verdade significava de fato. Ele sabia, de um modo que povos menos esclarecidos não poderiam saber, que o universo, sem a verdade, se desfaria e se perderia na noite eterna. Mais do que uma abstração, mais até do que um ideal, era a verdade que formava o tecido básico da existência (HOLLAND, 2008, 57).

Zaratustra dizia ter tido uma visão de Ahura-Mazdâ, cujo nome significa literalmente algo como "o Sábio Senhor" ou "o Senhor [da] Sabedoria”, e dele ter recebido a missão de pregar o valor mais alto, a Verdade/Retidão/Ordem. Kaikhosrov Irani, professor emérito de filosofia no City College of New York, esclarece que

\begin{abstract}
No mundo material, o bom espírito [Spenta-Mainyu; um epíteto de Ahura-Mazdâ] é bom precisamente porque promove Asha, isto é, encaminha o mundo na direção do estado de perfeição ideal. O espírito mau [Angra-Mainyu] é mau precisamente porque tenta frustrar a realização progressiva de Asha. É nesse aspecto da teologia gática [= dos Gâthâs de Zaratustra] que podemos ver por que Asha é interpretada como Verdade. Ela é a verdadeira figura da forma da existência Ideal [Mainyu; espiritual], e também o ideal em direção ao qual o mundo [ora] conflituoso progride. É a verdade ideal subjacente a toda existência. Nesse mesmo esquema podemos ver como Asha é interpretada como Retidão. A ação correta é aquela que está de acordo com Asha, aquela que faz avançar a realização de Asha. Essa é a doutrina da Lei Natural em uma de suas primeiríssimas aparições. Ela é o Princípio Cósmico que faz do cosmos o que ele é, e ao mesmo tempo fornece a base para a vida moral e o julgamento moral. Nesse sentido a ética de Zaratustra está fundamentada em uma teoria de lei natural de apreensão e aplicação de Asha, e não numa teoria prescritivista que fornece um conjunto de regras morais para se obedecer. Na medida em que o mundo físico é compreensivo e harmonioso, ele está de acordo com Asha. Eis porque Asha é interpretada como Ordem (IRANI, s/d: parág. 5-6; grifos [e inserções] nossos).
\end{abstract}

Conforme Xenofonte, as crianças persas dedicavam seu tempo na escola a aprender "a dizer a verdade, a não enganar e a não ter ganância" (Ciropédia, I, 6, 33) ${ }^{18}$. Na cosmogonia zoroastriana, a "Melhor Verdade" (avéstico Asha Vahishta; veteropersa Arta Vahishta; pálavi

17 Dêiókês em grego, provavelmente traduzindo Daiukkû ou Dayukku (*Dahyu-ka- em iraniano).

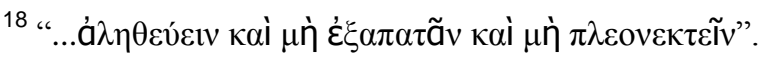


Ardwahisht; Ardibehesht), a quem é dedicada a Ardwahisht Yasht do Khorda Avesta [Yasht, 3], cria o fogo (invisível ou visível), secundada pelo velho deus iraniano do fogo, Âtar. Assim, o fogo é o elemento primário e a representação sensível de Asha (Yasna, 36.1: “Através do fogo nos aproximamos de ti, ó Ahura Mazdâ!").

A inscrição de Dario I [filho de] Hystaspes (Dârayavaush Vishtâspa) em Behistun (DB) é considerada como o discurso que dá início à ideologia formal da monarquia veteropersa $^{19}$. Essa inscrição trilíngue ${ }^{20}$ (trataremos aqui apenas do texto em veteropersa) que foi gravada num rochedo e copiada em tabuinhas e pergaminhos (DB§70) apresenta-se segundo um esquema temporal triádico, calcado na retórica religiosa zoroastriana $^{21}$, que evoca os reis do passado (DB§1-4), dá conta dos feitos do próprio Dario (\$5-54) e interpela os reis vindouros (§55-69). Um eloquente exemplo pregresso em defesa da "Verdade" é evocado em relação a um período de grandes convulsões no reino por ocasião da rebelião do "mago" Gaumâta, que proclamou ser Smérdis ${ }^{22}$ (então falecido); filho de Ciro, o Grande e irmão de Cambises II, enquanto este estava em campanha no Egito. Heródoto (Histórias, III.30.1-2) relata que Cambises havia matado Smérdis por temer perder para o irmão o trono da Pérsia, pois Smérdis havia sido o único persa a poder disparar com um arco enviado pelo rei da Etiópia $^{23}$, e Cambises tivera um sonho em que vira Smérdis sentado no trono real e tocando o céu com a cabeça. A inscrição de Dario em Behistun informa: "Quando Cambises foi para o Egito, depois disso o povo se tornou mau; depois disso a Mentira [de Gaumâta] se espalhou grandemente no reino, na Pérsia, na Média e nas outras províncias"24 (§10; DB coluna 1, linhas 33-35).

Os persas acreditavam que a difusão da mentira ameaça a própria ordem da existência; uma passagem do Avesta (Mihr Yasht do Khorda Avesta, 2 [Yasht, 10.2]) proclama

\footnotetext{
${ }^{19}$ Cf. Helena Wilhelmina Agatha Maria Sancisi-Weerdenburg [Heleen Sancisi-Weerdenburg] (1980), Yaunâ en Persai: Grieken en Perzen in een ander perspectief (tese de doutorado apresentada à Universidade de Leiden, Holanda); James E. Bowick, Hearing Darius: A Bakhtinian Study of the Voice of Darius in the Behistun Inscription, Herodotus' The Histories, and Ezra-Nehemiah (tese de mestrado apresentada ao McMaster Divinity College, Canadá).

${ }^{20}$ Nos idiomas elamita, babilônico e veteropersa.

${ }^{21}$ Cf. Yasna, 31.7-20; Yasna, 44; Zam Yasht, passim.

${ }^{22}$ Bardiya em veteropersa; Barziya em medo.

23 Bardiya/Smérdis era conhecido como tanyoxarces (Ctésias, Persica, 29.8; tanaoxares em Xenofonte, Ciropédia, 8.7, 11), do veteropersa *tanuwazraka, "corpulento". Por sua vez, Bardiya significa "grandalhão" (do proto-iraniano *bardz-, "ser alto").

24 “... Kambûjiya Mudrâyam ashiyava pasâva kâra arika abava pasâva drauga dahyauvâ vasiy abava utâ pârsaiy utâ mâdaiy utâ aniyâuvâ dahyushuvâ thâtiy ...”.
} 
que "o desgraçado que mente perante Mitra (mithrô-drukhsh; Mithra-druj), ó spitamida ${ }^{25}$, traz a morte para o país inteiro, de forma semelhante a cem fazedores do mal (kayadhas) lesando o [país] ordeiro" 26 . Mitra é o deus zoroastriano das mediações; como substantivo ordinário, a palavra mithra significa "contrato" e mithrô-drukhsh significa "aquele que quebra o vínculo/acordo/contrato/juramento”. Mitra é representado, em diversas tradições, como sendo um habilidoso arqueiro ${ }^{27}$.

Dirigindo-se a um sucessor legítimo ao trono iraniano, como ele considerava a si próprio, o Grande Rei proclama: "Dario o Rei diz: tu que deves ser rei doravante, proteje-te vigorosamente da Mentira; ao homem que for um seguidor da Mentira, pune-o bem, se pensares assim: 'Possa meu reino ter segurança!"’28 (\$55; DB coluna 4, linhas 36-40). Diz ainda Dario: "Tu que deves doravante ler esta inscrição, deixa-me fazer com que aquilo que foi feito por mim te convença; não toma isso por mentira” ${ }^{, 29}$ (§56; DB coluna 4, linhas 4143). A proclamação segue assim:

Dario o Rei diz: por esta razão Ahura-Mazdâ ajudou-me, e [também] os outros deuses que existem, pois eu não fui hostil [à fé], não fui um seguidor da Mentira, não fui um fazedor do errado (ou: falso em minhas ações) - nem eu nem minha família. Segundo a retidão me conduzi. Nem ao fraco nem ao poderoso fiz errado. Ao homem que cooperou com minha casa recompensei bem; àquele que me injuriou eu puni bem./ Dario o Rei diz: tu que deves ser rei doravante, ao homem que for um seguidor da Mentira ou àquele que for um fazedor do errado (ou: falso em suas ações), não lhes sê amigo, [e] pune-os bem ${ }^{30}$ (§63-64; DB, coluna 4, linhas 61-69).

\footnotetext{
${ }^{25}$ Da família sacerdotal de Spitâma, ancestral de Zaratustra.

26 “... mereñcaite vîspãm dainghaom mairyô mithrô-drukhsh spitama, yatha satem kayadhanãm avavat ashavajacit ...".

27 Cf. inúmeras passagens relacionando Mitra com flechas, mais as figuras 14 e 19, em Maarten Jozef Vermaseren (1963), Mithras, the Secret God [1959], trad. T. Megaw e V. Megaw. Chatto and Windus, Londres/Clarke + Irwin, Toronto, e Barnes and Noble, N. Iorque [reimpr. (2000) University of Michigan, Ann Arbor].

28 “... Dârayavaush khshâyathiya tuvam kâ khshâyathiya hya aparam âhy hacâ draugâ darsham patipayauvâ martiya hya draujana ahatiy avam ufrashtam parsâ yadiy avathâ maniyâhaiy dahyâushmaiy duruvâ ahatiy thâtiy ...".

29 : “... tuvam kâ hya; aparam imâm dipim patiparsâhy tya manâ kartam varnavatâm thuvâm mâtya draugam maniyâhay ...”.

30 “... Dârayavaush khshâyathiya avahyarâdiy Auramazdâ upastâm abara utâ ani; yâha bagâha tyaiy haijy yathâ naiy arika âham naiy draujana âham naiy zûrakara âham naiy adam naimaiy taumâ upariy arshtâm upariy âyam naiy shkaurim naiy tunuvatam zûra akunavam martiya hya hamata; khshâta manâ vithiyâ avam ubartam abaram hya viyanâthaya avam ufrastam aparsam thâtiy// Dârayavaush khshâyathiya tuvam kâ khshâyathiya hya aparam âhy martiya hya draujana ahatiy hyavâ zurakara ahatiy avaiy mâ daushtâ biyâ ufrashtâdiy parsâ thâtiy ...".
} 


\section{A FLECHA (VETEROPERSA ISHU [SÂNSCRITO ÍSHU], AVÉSTICO ISHU OU ASHTI, PÁlAVI TÎR, TIGR [DO AVÉSTICO TIGHRI-] OU SAR, FARSI ASHT; TIGR).}

A inscrição "B" de Dario o Grande em Naqsh-i Rustam (DNb), por vezes descrita como um "espelho para príncipes" (em farsi, andarz) em razão de expor as qualidades que Dario acredita que um rei deve ter e que supostamente ele próprio tinha, proclama: "Sou hábil com as mãos e com os pés. Como cavaleiro sou um bom cavaleiro ${ }^{31}$; como arqueiro ${ }^{32}$ sou um bom arqueiro, tanto a pé quanto a cavalo ${ }^{33}$. Como lanceiro sou um bom lanceiro, tanto a pé quanto a cavalo"34 ( $\$ 8 \mathrm{H}$; linhas 40-45). A lança (arshti; arshtish ${ }^{35}$; pálavi arst) era um equivalente "pedestre" e mais robusto da flecha ${ }^{36}$, embora de menor alcance; não é de nosso conhecimento que a retórica persa tenha feito associações diretas entre as lanças e a verdade, embora saibamos da existência de associações entre a verdade e as flechas.

No Rigveda (RV), escritura sagrada indiana muitas vezes estudada como importante paralelo cultural e linguístico ao Avesta, um hino às armas de guerra $\left(\mathrm{RV}, \mathrm{VI} .75^{37}=5^{\circ}\right.$ ashtaka, $1^{\circ}$ adhyaia, sukta XIV, varga XXII, 1) ${ }^{38}$, que Moriz ("Maurice”) Winternitz e

31 A palavra para "cavaleiro", asabâra (avéstico aspobâra, parto asbâr, bactriano asbarobido, pálavi asobâr/asubâr, farsi asvâr/savâr), deriva do veteropersa asa, "cavalo", e bâra (avéstico barate), "[aquele que] monta".

${ }^{32}$ A palavra usada indica mais amiúde, em textos posteriores, o "arqueiro a pé" (arqueiro da infantaria persa; sinônimo: thanuvabâra); o arqueiro a cavalo ficou mais especificamente conhecido como tirandaz, "flecheiro".

${ }^{33}$ Cf. tb. o selo de Xerxes I de Daskyleion (lat. Dascylium, Frígia helespontina) retratado em Maria Brosius (2000) (ed.), The Persian Empire from Cyrus II to Artaxerxes I. London Association of Classical Teachers, Londres, p. 50.

34 “... vainâmiy yâumainish amiy utâ dastaibiyâ utâ pâdaibiyâ asabâra uvâsabâra amiy thanuvaniya uthanuvaniya amiy utâ pastish utâ asabâra ârshtika amiy uvârshtika utâ pastish utâ asabâra ...”..

${ }^{35}$ No Vendîdâd, 17.43, arshtayascha. O vocábulo provém do verbo rish; aresh, "ferir; perfurar" (sânscrito arsh; aresh; sueco rista, "lacerar; rasgar"), donde arshti poder significar, dependendo do contexto, também "espada" [cf. Marco Antonio Canini (1882), Etudes Étymologigues. N. Loeocher, Turim, p. 48], ou qualquer projétil com ponta.

${ }^{36}$ Cf. a inscrição "A" de Dario em Naqsh-i Rustam, §4, linhas 43-47: "Então será conhecido por ti: a lança de um homem persa avançou até longe; de fato, um homem persa levou a batalha até bem longe da Pérsia" ("... pârsahyâ martiyahyâ dûraiy arshtish parâgmâta adataiy azdâ bavâtiy pârsa martiya dûrayapiy hacâ pârsâ partaram patiyajatâ thâtiy ...").

37 I.e., Mandala VI, hino 75.

${ }^{38}$ H. H. Wilson esclarece: "Armas, pessoas e implementos empregados na guerra são [aqui] considerados como deidades" [(1886) Rig-Veda Sanhitá. A collection of ancient Hindu hymns, constituting the fifth ashtaka, or book, of the Rig-Veda. N. Trübner \& Co., Londres, p. 23). Ralph Griffith comenta: "Os objetos [ali] deificados são a armadura e as armas de guerra, o auriga, a biga, os cavalos etc., e as deidades tutelares [são aquelas] mencionadas ou invocadas no hino" [Ralph Thomas Hotchkin Griffith (1895), The Hymns of the Atharva Veda, 
Srinivasa Sarma acreditam que "pode ter sido um canto de batalha que depois foi transformado numa bendição de batalha" (WINTERNITZ \& SARMA, 1981, 100), menciona como a prece interfere com a eficácia do tiro de flecha: "Livre da corda do arco, voa para longe, ó flecha, afiada por nossa prece (brahma-saṃsite)./ Vai até os inimigos, atinge-os na casa deles, e não deixa ninguém vivo!"39. No Avesta, a flecha é símbolo de rapidez e precisão (Yasna, 52.28; Tishtar Yasht do Khorda Avesta, 6 [Yasht, 8.6]); contudo, aprendemos ali (Mihr Yasht do Khorda Avesta, 38-39 [Yasht, 10.38-39]) ${ }^{40}$ que aqueles que mentem perante Mitra (mithrô-drujãm), apesar de suas "flechas com penas de falcão ${ }^{41}$, atiradas pela corda do arco bem tensionado ${ }^{42,}$, não atingem seu alvo (= não alcançam seus objetivos), pois Mitra bloqueia seus disparos (ou evita seu dano quando o disparo é certeiro; ou desvia a flecha ${ }^{43}$ por meio do vento - Mihr Yasht do Khorda Avesta, 21 [Yasht, 10.21]) ${ }^{44}$. A mentira, como qualquer ato pecaminoso, retorna ao mentiroso como uma flecha ${ }^{45}$ na contramão (Mihr Yasht do Khorda Avesta, 20 [Yasht, 10.20]), e prejudica o próprio mentiroso com a velocidade de

2 vols., v. 1. E. J. Lazarus \& Co., Benares [reed. (1968) Chowkhamba Sanskrit Series Office, 1 Benares/Varanasi], p. 384).

39 “avasrșțā parā pata śaravye brahmasaṃśite/ghachāmitrān pra padyasva mānūṣāṃ kaṃ canoc chiṣaḥ”. Nossa tradução segue a de Ralph Griffith [ANÔN. (1973). The Hymns of the Rgveda, p. 332]: "Loosed from the Bowstring fly away, thou Arrow, sharpened by our prayer./ Go to the foemen, strike them home, and let not one be left alive". H. H. Wilson (op. cit., p. 27) traduz: "Arrow, whetted by charms, fly when discharged: go: light amongst the adversaries: spare no one of the enemies", e acrescenta: "[cf.] Sáma Veda, II.1213 [Sama-Veda, 2a parte, livro IX, cap. III, vs. 8 (agha V), 3]; Yajur-Veda, 17.45"; cf. Atharva-Veda, livro III, hino XIX, 8.

40 "ishavascit aêshãm erezifyô-parena, huthakhtat haca thanvanât, jya-jataonghô vazemna, ashemnô-vîdhô bavaiti, ýatha grañtô upa-tbishtô, apaiti-zañtô mithnâiti, mithrô ýô vouru-gaoyaoitish...”. Na tradução de James Darmesteter: "Their falcon-feathered arrows, shot from the string of the well-bent bow, fly towards the mark, and hit it not, as Mithra, the lord of wide pastures, angry, offended, and unsatisfied, comes and meets them (...)"(...)" \{J. Darmesteter (1880-85) (trad.). The Zend Avesta, v. I: Vendîdâd; v. II: Sirozahs, Yasts and Nyayis (Sacred Books of the East, ed. F. M. Müller, volumes 4 e 23). University Press, Oxford [reimpr. (1965) Motilal Banarsidass, Delhi]\}. Na tradução de William Malandra (op. cit.): "Even their eagle-feathered arrows, propelled by the bowstring, flying from a well-drawn bow, strike no wounds, since Mithra of wide pastures, angered (at) having been treated with enmity, is hostile (at) not having been acknowledged (...)".

${ }^{41}$ Cf. Khorda Avesta, Yasht, 10.101; Vidêvdât/Vendîdâd, 17.9.

${ }^{42}$ Cf. Khorda Avesta, Yasht, 13.72; Vidêvdât/Vendîdâd, 4.49.

43 James Darmesteter (op. cit.) opta por "spear" (lança). Prods Oktor Skjærvø [(2005) Introduction to Zoroastrianism. Harvard University (Near Eastern Languages School), Cambridge, p. 96] prefere "arrow" (flecha).

${ }^{44}$ Cf. tb., sobre a proteção daqueles que são ajudados por Mitra contra lanças e flechas, o Mihr Yasht do Khorda Avesta, 24 [Yasht, 10.24].

${ }^{45}$ Opção, p. ex., da tradução de Skjærvø (op. cit.), p. 96. Darmesteter (op. cit.) prefere “spear” (lança). 
uma flecha: "Assim como a flecha [chega] acolá, do mesmo modo [o pecado chega] na conta de alguém"46. (Frahang-i Ôim, 10).

Os símbolos estéticos do poder real persa eram uma túnica, um arco e um escudo. $\mathrm{O}$ relevo de Behistun mostra Dario de pé segurando um arco em sua mão esquerda e estendendo a mão direita em direção a um disco alado do qual emerge o deus Ahura-Mazdâ. O relevo da tumba de Dario em Naqsh-i Rustam mostra o grande rei com essas mesmas características. As moedas aquemênidas (cf. BRIANT, 2002, 213-214, esp. 214 fig. 17) frequentemente mostram o rei persa segurando um arco (avéstico thanvana; thanvara; pálavi kamân) com a mão esquerda e flechas com a mão direita, ou mesmo disparando flechas; por essa razão, essas moedas ficaram conhecidas em grego como toxótai, "arqueiros" ${ }^{47}$. Do exemplo de Roxana ${ }^{48}$, meia irmã do sátrapa Terituchmes, podemos inferir que as mulheres também podiam ser $\operatorname{arqueiras~talentosas~}^{49}$ (GARCÍA SÁNCHEZ 2009: 199 n. 87). Acreditava-se, no antigo Irã, que a própria fronteira entre terras iranianas e turanianas (dos turcomanos) havia sido determinada por um disparo de flecha de Erekhsha (Arash) ${ }^{50}$. Os gregos, que valorizavam o combate corpo a corpo, consideravam o arco como arma própria dos covardes (GARCíA SÁNCHEZ 2009: 144 n. 243), apesar das representações e dos feitos de Héracles com arco e flecha (ANKLESARIA 1920: 80-83).

Uma aljava persa costumava ser carregada com 30 flechas (Vidêvdât/Vendîdâd, 14.9; Tabarî, cf. Theodor NÖLDEKE 1879: $249^{51}$ ) e dois arcos (cada um com cerca de $150 \mathrm{~cm}$ de

\footnotetext{
46 "yatha ashtish paityahmi atha bunem â". Tradução segundo Raham Asha (2009), Avesta Glossary: $\boldsymbol{A}$ glossary of Avesta words and their Pārsig equivalents, based on the Zand, the so-called Frahang I ōim: ēk - Text and Gramatical Notes. K. R. Cama Oriental Institute, Bombaim, p. 115.

${ }^{47}$ Plutarco, Agesilaus, 15.6; Artaxerxes, 20.4.

${ }^{48}$ Rôxánê em grego, avéstico Raokhshna ou Roshanak "luminosa; brilhante; esplendorosa", pálavi Rakhsh ou Rokhsân; persa Rokhsâna ou Rôshanâ.

${ }^{49}$ Ctésias, F 15, 55 [FGrHist. 688].

50 Erekhsha "das flechas rápidas" (khshviwi-ishush; khshvivi ishu; tb. um epíteto de Mitra), "possuidor das flechas mais rápidas (khshviwi-ishvatemô) entre os árias" (e de quem existe uma imponente estátua em Yazd), é exaltado na Yasht, 8.6 [Tishtar Yasht do Khorda Avesta, 6]. "A lenda diz que Arash-i Kamangir [Erekhsha] era o melhor arqueiro do exército iraniano. Quando Manuchihr e Afrâsiyâb se propuseram a fazer a paz e fixar a fronteira entre o Irã e Turan [as terras dos turcomanos], foi estipulado que Arash deveria subir o Monte Damâvand [Monte Airyô.khshutha (Khshaotha) na Yasht, 8.6] e dali deveria disparar uma flecha em direção ao leste, e que o lugar onde a flecha caísse deveria formar a fronteira entre os dois reinos. Então Arash subiu a montanha e disparou em direção ao leste uma seta, cujo vôo se estendeu da aurora até o meio dia, quando ela caiu nas margens do Jeyhun (o rio Oxus) [Monte Khvanvant (Hvanvañt; 'Ensolarado') na Yasht, 8.6 e 8.38]' [Mukesh Kumar Sinha (2005), The Persian World. Understanding People, Polity and Life in Iran, Afghanistan and Tajikistan. Hope India Publications, Gurgaon, pág. não numerada). Cf. ainda Behramgore Tahmuras ANKLESARIA 1920: 79-83.

51 "Köcher enthaltende 2 Bogen mit den Sehnen daran und 30 Pfeile".
} 
comprimento), com alcance ideal de 40-50m, embora as flechas pudessem alcançar até $450 \mathrm{~m}$ com menor precisão. Duas inscrições de Dario em Naqsh-i Rustam ("D" e "C") acompanham relevos que mostram Aspacanâ (grego Aspathines) como vasabâra, isto é, carregador do arco do rei [e tb. de seu machado de batalha (isuvâm)], e Gaubaruva (gr. Góbrias) como arshtibara, carregador da lança do rei. O relevo de Behistun mostra um vasabâra e um arshtibara acompanhando Dario.

Heródoto relata (Histórias, V.105) que o rei Dario, após tomar conhecimento que Sardis, a capital da Lídia (então uma província persa), fora incendiada pelos atenienses e jônios, e sabendo que seria bem difícil vingar-se dos distantes atenienses, dispara uma flecha para o alto na direção do céu e faz um pedido: "Oh Deus! Concede-me a graça de vingar-me dos atenienses!". O disparo da flecha era simbolicamente associado ao cumprimento da Verdade/Retidão/Ordem ou, de modo equivalente, ao afastamento da Mentira/Erro/Desordem (druj), como podemos ver numa passagem do Avesta: “Ahura-Mazdâ respondeu: (...) 'Diga alto aquelas palavras dos Gâthâs (...), e [a Mentira/Erro/Desordem de] Nasu ${ }^{52}$ irá voar para longe, ó Zaratustra Spitama, como a flecha bem disparada, como o feltro [da tenda?] do ano passado $^{53}$, como a veste anual (= a vegetação) da terra"54 (Vidêvdât/Vendîdâd, 9.46). Uma passagem de Heródoto (Histórias, III.34-35) conta um episódio trágico que também revela uma associação simbólica entre o disparo da flecha e o cumprimento da Verdade:

(c. 34) [Fala Cambises ao seu vizir:] "Prexaspes, que tipo de homem os persas pensam que sou? Que dizem eles sobre mim?". "Senhor, eles te elogiam muito em relação a tudo, exceto em um aspecto: eles dizem que amas demasiadamente o vinho". Essa foi a resposta que Prexaspes deu quanto à opinião dos persas, e então o rei, cheio de raiva, respondeu: "Se eles dizem que bebo muito vinho, que isso me obnubila os sentidos e me faz perder o juízo, então suas palavras anteriores sobre mim eram mentirosas". (...) Alguns dias mais tarde (...)

(c. 35) (...) Cambises disse a Prexaspes: "Julga agora por ti mesmo se os persas estão dizendo a verdade, ou se não são eles que estão fora do juízo ao dizerem o que dizem. Lá está teu filho ${ }^{55}$, de pé junto à entrada. Se eu atirar uma flecha nele, e se o atingir bem no coração, isso provará que os persas estão falando tolices; se eu errar poderás dizer que os persas estão certos e que estou fora do meu juízo". Falando assim ele tensionou o arco e disparou a flecha, atingindo o menino, que caiu morto no chão. Cambises ordenou aos seus homens que abrissem o corpo e examinassem a

\footnotetext{
52 Um dos demônios do Zoroastrismo, associado à contaminação, e aqui uma personificação da mentira contagiosa. Cf. Vidêvdât/Vendîdâd, 9.45 (drukhsh ... nasu) e 9.48 (drukhsh ýâ nasush).

${ }^{53}$ Nota de James Darmesteter: "O feltro de uma oba [tenda comunal] feita para uma estação (?). Cf. Vendîdâd, 8.1 ".

54 “âat mraot ahurô mazdao, ime vaca framrva yôi heñti gâthâhva ..., mãnayen bâ Spitama Zarathushtra aipi tâ nasush zgathaite yatha ishush hvâthaxtô yatha vâ nematô tarô yâre yatha vâ rathwya varena".

${ }^{55}$ Conforme Heródoto, esse filho era copeiro do rei.
} 
ferida. Quando se verificou que a flecha havia trespassado seu coração ele virou-se para o pai do menino e disse satisfeito e risonho: "Agora vês com clareza que não estou louco, e que os persas estão fora do juízo. Agora dize-me: conheces mais algum mortal que possa disparar uma flecha com tanta precisão?". Prexaspes, vendo que o rei estava fora de si, e temendo por si mesmo, respondeu: "Oh Senhor, não penso que o próprio deus tivesse feito um disparo tão bom" (...)

(trad. modificada a partir de HERÓDOTO, 1862).

Esse chocante relato grego sobre um déspota persa, com toda a aparência de ser uma distorção propagandística, segundo Allan Griffiths (2001) parece ocultar "uma representação icônica malentendida de um ritual religioso persa" ${ }^{\text {"56 }}$ : com base na decoração em relevo de um grande caldeirão em terracota encontrado em um mithraeum em Mainz ${ }^{57}$, Roger BECK (2004: 58) apontou que uma cerimônia iniciática fundamental no culto de Mitra, à qual chamou de "the archery of the Father", envolvia a encenação de um disparo, por um idoso sentado (o Pater, talvez representando o próprio Mitra), de uma seta em direção a um garoto escoltado por um mistagogo adulto, ocasionando a morte ritual do garoto. A maior parte dos rituais mitraicos envolvia uma reencenação de episódios da narrativa mítica da vida do deus, e um importante episódio desta, "o milagre da água", envolvia fazer a água brotar de uma rocha após atingi-la com uma flecha (MERKELBACH 1995: 2-5), tendo BECK (2004 58) proposto que "a arqueria ritual do Pai inicia [o garoto], mimetizando a arqueria mítica de Mitra". Por essa interpretação, fica evidente que estudar a retórica dos textos persas ou dos textos gregos que alegam reproduzir discursos persas, bem como a estética dos persas e das culturas persianizadas, sem levar em conta um contexto transcultural maior, condena essa empreitada à incompletude epistêmica.

\section{CONCLUSÃO}

Palavras são como flechas: se forem bem encaminhadas, elas podem chegar ao alvo e cumprir o seu propósito, e também podem ferir. $\mathrm{O}$ dano que podem causar não pode ser sempre previsto, pois palavras e flechas tem penetração variável e podem desviar da meta.

\footnotetext{
56 "it looks as though behind Herodotos' story lies a misunderstood iconic representation of a Persian religious ritual".

${ }^{57}$ Heinz Günter Horn (1994), "Das Mainzer Mithrasgefäß”. Mainzer archäologischen Zeitschrift, 1: 21-66 (cf. pp. 25-28). O tipo de cerâmica do caldeirão sugere uma datação no primeiro quarto do séc. II a.C. (BECK 2004: $58)$.
} 
Além disso, as palavras não retornam depois de proferidas, nem as flechas após serem disparadas. Palavras e flechas devem, portanto, ser empregadas com sabedoria.

Entre os antigos iranianos, essa sabedoria esteve sempre associada à Verdade/Retidão/Ordem (Asha), um conceito de lugar privilegiado na linguagem religiosa zoroastriana, na retórica política dos soberanos Aquemênidas e na estética dos povos da antiga Pérsia. Podemos afirmar, evocando Nietzsche, que a linguagem (retórica ou estética) dos antigos persas é a expressão da força que empregaram para fazer valer Asha como aquilo que "é eficiente e impressiona" - como uma flecha bem disparada -, e de fazer com que suas flechas pudessem ter a força da Verdade. 


\section{REFERÊNCIAS BIBLIOGRÁFICAS}

\section{Fontes Primárias}

ANÔN. Avesta (Yasna, Khorda Avesta, Visperad, Vendidad [Videvdat], Fragments) (s/d). Disponível em: 〈http://www.avesta.org/>.

ANÔN. Old Persian Texts (s/d). [baseado em Roland G. Kent, Old Persian, 1953]. Disponível em: 〈http://www.avesta.org/op/op.htm>.

ANÔN. The inscriptions of Old Persian cuneiform of the Achaemenian emperors, ed. Ralph Norman Sharp. Central Council of the Celebration of the 25th Century of the Foundation of the Iranian Empire, Teerã (1964).

ANÔN. The Hymns of the Rgveda, ed. Ralph Griffith [1896 (ed. revista)]. Motilal Barnasidass, Delhi (1973).[c/ várias reedições].

ANÔN. Zamyâd Yast: Yasht 19 of the Younger Avesta. Text, translation, commentary, ed. Helmut Humbach e Pallan R. Ichaporia. Otto Harrassowitz, Wiesbaden (1998).

HERODOTUS . Histories, 4 vols., trad. G. Rawlinson, com a assistência de H. Rawlinson e J. G. Wilkinson [1858-1860]. J. Murray, Londres (1862). Disponível em: $<$ http://classics.mit.edu//Herodotus/history.html >.

XENOPHON. Cyropaedia, 2 vols. (Loeb Classical Library) trad. W. Miller. Heinemann, Londres/Harvard University Press, Cambridge (Massachusetts) (1914 [reimpr. 1968, 1979]).

\section{Fontes Secundárias}

AHN, G. (1992) Religiöse Herrscherlegitimation im Achämenidischen Iran. Die Voraussetzung und die Struktur ihrer Argumentation. Brill, Leiden/Peeters, Louvain.

ANKLESARIA, B. T. (1920) "Erekhsha, the Archer and His Arrow". Proceedings and Transactions of the First Oriental Conference, Poona (5-7/11/1919), vol. 1. Bhandarkar Oriental Research Institute, Poona. 
BECK, R. (2004) "Ritual, Myth, doctrine, and Initiation in the Mysteries of Mithras: new evidence from a cult vessel". Em: Beck on Mithraism: Collected Works With New Essays. Ashgate, Aldershot (Hampshire)/Burlington (Vermont), pp. 55-110 [publ. original (2000) em Journal of Roman Studies, 90: 145-80].

BRIANT, P. (2002) From Cyrus to Alexander: A History of the Persian Empire [1996], tr. Peter Daniels. Eisenbrauns, Winona Lake (Indiana).

DREWS, R. (2004) Early Riders: The beginnings of mounted warfare in Asia and Europe. Routledge, Londres/Nova Iorque.

GARCÍA SÁNCHEZ, M. (2009) El Gran Rey de Persia: formas de representación de la alteridad persa en el imaginario griego. Edicions Universitat Barcelona, Barcelona.

GRIFFITHS, A (2001). "'Your shooting is divine, my lord': Kambyses at Hdt. 3.35". Disponível em: <http://www.ucl.ac.uk/classics/staff/honorarypositions/alangriffiths/AHG3-035>. Acesso em: 06 dez. 2014.

HOLlAND, T. (2008) Fogo Persa. O primeiro império mundial e a batalha pelo ocidente [2005], trad. L. A. Aguiar. Record, Rio de Janeiro.

IRANI, K. D. (s/d) "The Concept of Asha: a philosophical analysis". Em: Dina G. Mclntyre (ed.), An Introduction to the Gathas of Zarathushtra [12 ensaios, 1989-1990], vol. 2. Disponível em: <www.zarathushtra.com/z/article/dgm/vol2.htm\#article 2>. Acesso em: 16 dez. 2014.MERKELBACH, R. (1995) “Das Mainzer Mithrasgefäß”. Zeitschrift für Papyrologie und Epigraphik, 108: 1-6.

NIETZSCHE, F. W. (1999) Curso de Retórica [1872?], trad. e apresentação Thelma Lessa da Fonseca (Cadernos de Tradução [Dep. de Filosofia, USP], 4), 69 pp.

NIETZSCHE, F. W. (2014) Also sprach Zarathustra [1885]; Kritische Studienausgabe, ed. G. Colli e M. Montinari, $14^{\mathrm{a}}$ ed. Walter de Gruyter, Berlim/DTV, Munique.

NIETZSCHE, F. W. (2014) Ecce Homo [1888]. Em: Der Fall Wagner. Götzen-Dämmerung. Der Antichrist. Ecce homo. Dionysos-Dithyramben. Nietzsche contra Wagner; Kritische Studienausgabe, ed. G. Colli e M. Montinari, $11^{\mathrm{a}}$ ed. Walter de Gruyter, Berlim/DTV, Munique.

NÖLDEKE, T. (1879) Geschichte der Perser und Araber zur Zeit der Sasaniden. Aus der arabischen Chronik des Tabari [= Ta'rîkh ar-Rusul wa al-Mulûk] übersetzt und mit 
ausführlichen Erläuterungen und Ergänzungen versehn. E. J. Brill, Leiden [reimpr. 1973, Akademische Druck- und Verlagsanstalt, Graz].

WINTERNITZ, M., SARMA, S. (1981) A History of Indian Literature, I: Introduction, Veda, Epics, Puranas and Tantras [tradução e edição ampliada de Moriz Winternitz, (1905) Geschichte der Indischen Litteratur, vol. I]. Motilal Barnasidass, Delhi [c/ várias reimpressões]. 